\title{
High-Performance Liquid Chromatographic Method for Analysis of Emtricitabine in Rat Plasma: Method Development, Validation and Application to a Pharmacokinetic Study
}

\author{
Gurinder Singh and Roopa S. Pai \\ Department of Pharmaceutics, Faculty of Pharmacy, Al-Ameen College of Pharmacy, Near Lal Bagh Main gate, Hosur Road, \\ Bangalore, Karnataka 560027, India \\ Correspondence should be addressed to Roopa S. Pai; roopaspai@yahoo.com
}

Received 16 August 2013; Accepted 8 October 2013

Academic Editors: F. Couderc, C. Fanali, J. Millership, and F. J. Señoráns

Copyright (C) 2013 G. Singh and R. S. Pai. This is an open access article distributed under the Creative Commons Attribution License, which permits unrestricted use, distribution, and reproduction in any medium, provided the original work is properly cited.

\begin{abstract}
A new reverse phase liquid chromatographic method for the investigation of emtricitabine in rat plasma was developed after oral administration to Wistar rats. The desired chromatographic separation was achieved on Phenomenex $\mathrm{C}_{18}$ column ( $250 \mathrm{~mm}$ $\times 4.6 \mathrm{~mm}$ I.D., $5 \mu \mathrm{m}$ ) column, under isocratic conditions using UV detection at $280 \mathrm{~nm}$. The optimized mobile phase consisted of a mixture of $10 \mathrm{mM}$ potassium dihydrogen phosphate buffer- (adjusted to $\mathrm{pH} 6.8$ ) methanol-2\% acetic acid in a ratio of $(73: 25: 2, \mathrm{v} / \mathrm{v} / \mathrm{v})$ at a flow rate of $1 \mathrm{~mL} \mathrm{~min}^{-1}$. The system was found to produce sharp and well-resolved peaks for emtricitabine with retention time of $5.78 \mathrm{~min}$. The linear regression analysis for the calibration curves showed a good linear correlation over the concentration range $0.050-3.0 \mu \mathrm{g} \mathrm{mL}^{-1}$, with determination coefficients, $R^{2}$, exceeding 0.9970 . The limits of detection (LOD) and quantitation (LOQ) were found to be $0.016 \mu \mathrm{g} \mathrm{mL}^{-1}$ and $0.049 \mu \mathrm{g} \mathrm{mL}^{-1}$, respectively. The method was successfully applied for the pharmacokinetic in rats. Emtricitabine concentration in plasma reached $\left(C_{\max }\right)$ was $1.357 \mu \mathrm{g} \mathrm{mL} \mathrm{L}^{-1}$ about $2 \mathrm{~h}$ after oral administration of $15 \mathrm{mg} / \mathrm{kg} / \mathrm{rat}$. The $\mathrm{AUC}_{0-24}$ was $12.175 \mu \mathrm{g} \mathrm{mL} \mathrm{L}^{-1} * \mathrm{~h}$ and the apparent elimination half-life $\left(t_{1 / 2}\right)$ was $8.153 \mathrm{~h}$. This method was found to be suitable for examining emtricitabine concentration in rats, after oral administration of emtricitabine in a single dose.
\end{abstract}

\section{Introduction}

Emtricitabine (5-fluoro-1-(2R, 5S)-[2-(hydroxymethyl)-1,3oxathiolan-5-yl]cytosine) (Figure 1(a)) is a potent deoxycytidine nucleoside reverse transcriptase inhibitor for the treatment of human immunodeficiency virus (HIV) infection [1]. In adults, emtricitabine recommended dose is $200 \mathrm{mg}$ once a day (QD) [2]. Both in vitro [3] and in vivo [4] testing demonstrated that emtricitabine presents enough potential to be tested in the prevention of HIV-1, either alone or in combination [5].

A few HPLC and a brief reference to one UPLC method for simultaneous determination of emtricitabine in combination with other antiretroviral drugs in human plasma and rats have been described in the literature, mainly with the objective of method development for application to a bioequivalence study [6-8]. A simultaneous determination of emtricitabine and tenofovir in human plasma was described [9]. HPLC-UV detection method was developed for simultaneous determination of emtricitabine and tenofovir in tablet dosage form with LOQ of $0.091 \mu \mathrm{g} \mathrm{mL}^{-1}$ [10]. A rapid RP-HPLC method for a combination of tenofovir disoproxil fumarate, emtricitabine, and efavirenz was developed and subjected to forced degradation studies with LOQ of emtricitabine that was $1.19 \mu \mathrm{g} \mathrm{mL}^{-1}$ [11]. A validated RPHPLC method for the estimation of emtricitabine was not appropriate for detection of low emtricitabine concentration in capsules. In this method, the LOQ value was found to be $16.786 \mu \mathrm{g} \mathrm{mL}^{-1}$ and retention time was more than $9.341 \mathrm{~min}$ [12]. In the above reported HPLC methods, acetonitrile was employed as the organic phase. It is a toxic chemical as it can cause pollution and health hazards to humans and animals [13]. 


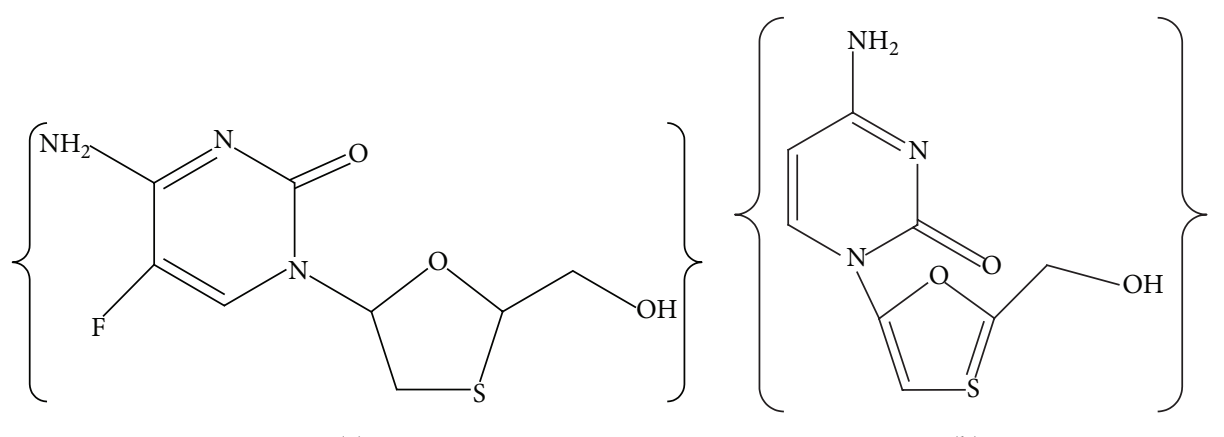

(a)

(b)

FIGURE 1: Chemical structure of emtricitabine (a) and lamivudine (b).

The purpose of the present study was to develop and validate a simple and time-saving RP-HPLC method with UV detection for the investigation of emtricitabine after oral administration to Wistar rats. The method was validated according to Food and Drug Administration (FDA) and International Conference on Harmonization (ICH) guidelines with respect to linearity, precision, accuracy, and specificity and stability studies $[14,15]$. Lamivudine $\left(0.8 \mu \mathrm{g} \mathrm{mL}^{-1}\right)$ was used as an internal standard (IS).

\section{Experimental}

2.1. Materials and Reagents. Emtricitabine and lamivudine (Figure 1(b)) (99.8\% w/w and 98.7\% w/w, HPLC) were provided ex-gratis by M/S Cipla Laboratories, Mumbai, India. HPLC grade methanol was purchased from SD fine-chem limited (Mumbai, India). Deionized water used in all the experiments was passed through a Milli-Q water purification system $(18.2 \mathrm{M} \Omega / \mathrm{cm})$ Millipore (Bangalore, Karnataka, India).

2.2. Instrumentation. The HPLC (Shimadzu, Kyoto, Japan) instrument was equipped with binary pump and SPD20AVP UV detector. Sample injection was done by Rheodyne injector with a $50 \mu \mathrm{L}$ loop and a computer running Varian workstation version 6.42 software for data acquisition and processing. The chromatographic analysis was carried out on Phenomenex $\mathrm{C}_{18}$ column $(250 \mathrm{~mm} \times 4.6 \mathrm{~mm}$ I.D., $5 \mu \mathrm{m})$.

2.3. Chromatographic Conditions. Chromatographic separation was achieved using Phenomenex $\mathrm{C}_{18}$ column. The mobile phase was composed of $10 \mathrm{mM}$ potassium dihydrogen phosphate buffer (adjusted to $\mathrm{pH}$ 6.8)-methanol-2\% acetic acid in a ratio of $73: 25: 2(\mathrm{v} / \mathrm{v} / \mathrm{v})$ run under isocratic elution

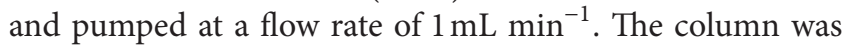
thermostated at $30^{\circ} \mathrm{C}$. Under these conditions the run time was less than $8 \mathrm{~min}$.

2.4. Optimization and Chromatographic Method Development. Trial experiments were carried out initially, in order to choose most appropriate solvent system for precise analysis and to achieve good resolution. Column chemistry, solvent type, solvent ratio (volume of organic solvents in the mobile phase), flow rate detection, and wavelength were varied to establish the chromatographic conditions giving the good separation. On the basis of time required for analysis, sensitivity of the assay, resolution time, and use of readily available cost-effective solvents, the aptness of the mobile phase and the flow rate was decided. These included water-methanol (50:50, v/v), $10 \mathrm{mM} \mathrm{pH} 6.8 \mathrm{PBS}-$ methanol $(50: 50, \mathrm{v} / \mathrm{v})$, $10 \mathrm{mM}$ pH 6.8 PBS-methanol $(70: 30, \mathrm{v} / \mathrm{v}), 10 \mathrm{mM}$ pH 6.8 PBS-methanol-2\% acetic acid $(70: 25: 5, \mathrm{v} / \mathrm{v} / \mathrm{v})$, and $10 \mathrm{mM}$ pH 6.8 PBS-methanol-2\% acetic acid (73:25:2, v/v/v). A mobile phase system comprised of $10 \mathrm{mM}$ potassium dihydrogen phosphate buffer ( $\mathrm{pH}$ 6.8)-methanol-2\% acetic acid $(73: 25: 2, \mathrm{v} / \mathrm{v} / \mathrm{v})$ at a flow rate of $1 \mathrm{~mL} \mathrm{~min}^{-1}$ was found to be optimum. The experimental work was performed in an airconditioned room maintained at $20-25^{\circ} \mathrm{C}$.

2.5. Preparation of Calibration Curve (CC) and Quality Control Samples (QC). Eight-point calibration curve (CC) was prepared by serial dilution of emtricitabine stock solution $\left(100 \mu \mathrm{g} \mathrm{mL}^{-1}\right)$ in the range of $0.050,0.1,0.5,1.0,1.5,2.0$, 2.5 , and $3 \mu \mathrm{g} \mathrm{mL}^{-1}$ that were obtained by measuring the required amount of $100 \mu \mathrm{g} \mathrm{mL}^{-1}$ working standard solution, mixed with a sufficient quantity of mobile phase and making up to $10 \mathrm{~mL}$. Similarly, six standard solutions were prepared by serial dilution of emtricitabine stock solution $\left(10 \mu \mathrm{g} \mathrm{mL}^{-1}\right)$ in the range of $0.005,0.010,0.020,0.030,0.040$ and $0.050 \mu \mathrm{g} \mathrm{mL}^{-1}$. Six standard solutions were obtained from the $10 \mu \mathrm{g} \mathrm{mL}^{-1}$ working standard solution, in order to determine the LOD and LOQ of the method.

Calibration standards were prepared daily by spiking $100 \mu \mathrm{L}$ of blank plasma with $10 \mu \mathrm{L}$ of the appropriate working solution resulting in concentrations of $0.050,0.1,0.5,1.0$, $1.5,2.0,2.5$, and $3 \mu \mathrm{g} \mathrm{mL}^{-1}$ and $0.005,0.010,0.020,0.030$, 0.040 , and $0.050 \mu \mathrm{g} \mathrm{mL}^{-1}$, respectively, of emtricitabine. Stock solution $\left(0.8 \mu \mathrm{g} \mathrm{mL}^{-1}\right)$ of lamivudine (I.S) was prepared in methanol and stored at $-20^{\circ} \mathrm{C}$. The solutions were stable for one day when stored at room temperature $\left(20-25^{\circ} \mathrm{C}\right)$. The stock and standard solutions) were prepared on a daily basis and stored in the dark at about $5^{\circ} \mathrm{C}$. All solutions were used on the day they were prepared.

Quality control (QC) samples (low quality control (LQC), $0.1 \mu \mathrm{g} \mathrm{mL}^{-1}$; medium quality control (MQC), $1.0 \mu \mathrm{g} \mathrm{mL}^{-1}$; 
high quality control (HQC), $2.5 \mu \mathrm{g} \mathrm{mL}^{-1}$; limit of quantification (LOQ), $0.049 \mu \mathrm{g} \mathrm{mL}^{-1}$ were prepared by spiking $0.1 \mathrm{~mL}$ aliquot of blank plasma with $10 \mu \mathrm{L}$ of spiking solution of drug as well as the IS. All solutions were stored in the refrigerator at $4.0 \pm 2.0^{\circ} \mathrm{C}$. The bulk spiked CC and QC samples were stored at $-20^{\circ} \mathrm{C}$ and brought to room temperature before use.

2.6. Sample Preparation. To a $50 \mu \mathrm{L}$ of rat plasma, $10 \mu \mathrm{L}$ of IS and $100 \mu \mathrm{L}$ of emtricitabine were added and the mixture was incubated at $37^{\circ} \mathrm{C}$ for $1 \mathrm{~h}$. Emtricitabine was then extracted using $30 \mu \mathrm{L}$ of acetonitrile followed by vortexing for $2 \mathrm{~min}$. After vortexing, the samples were subjected to centrifuge at $12,000 \times \mathrm{g}$ for $10 \mathrm{~min}$. The supernatant was decanted into a china dish and evaporated to dryness at room temperature. This was further reconstituted with $100 \mu \mathrm{L}$ of mobile phase and vortexed for $30 \mathrm{~s}$ and $20 \mu \mathrm{L}$ was injected into an HPLC system. Emtricitabine was detected at a wavelength of $280 \mathrm{~nm}$.

2.7. Method Validation Study. The developed method was validated as per ICH guidelines using emtricitabine with respect to the following parameters: accuracy, precision, LOD, LOQ, specificity, stability, and system suitability.

2.7.1. Linearity. For testing linearity, seven calibration standards were prepared in the concentration range of $0.05-$ $3.0 \mu \mathrm{g} \mathrm{mL}^{-1}\left(0.050,0.1,0.5,1.5,1.0,2.0,2.5\right.$, and $\left.3.0 \mu \mathrm{g} \mathrm{m}^{-1}\right)$. Standard curve was achieved by plotting peak area against concentration, and the evaluation of linearity was completed by linear regression analysis using least square method.

2.7.2. Limit of Detection and Limit of Quantitation. Normally, limit of detection (LOD) and limit of quantitation (LOQ) are estimated at a signal to noise ratio of $3: 1$ and $10: 1$, respectively. LOD and LOQ were determined based on the response and slope of a specific calibration curve obtained from six standard solutions $(0.005,0.010,0.020,0.030,0.040$, and $0.050 \mu \mathrm{g} \mathrm{m}^{-1}$ ) that were in proximity of these limit concentration values.

2.7.3. Selectivity, Specificity, and Linearity. Selectivity was verified by analyzing the blank plasma from rats to test interference at the analyte retention times. By employing the proposed extraction procedure each blank plasma sample was tested and then compared with the results of plasma samples spiked with emtricitabine $(n=6)$ in calibration standard to ensure no interference of emtricitabine from plasma.

Spiked plasma samples that contained increasing concentrations of emtricitabine from 0.050 to $3.0 \mu \mathrm{g} \mathrm{mL}^{-1}$ were analyzed according to the procedure described above. The linearity was detected by calculating the correlation coefficient $(r)$ of the curves by means of least-squared linear regression method. All calibration curves of emtricitabine were constructed prior to the experiments with correlation coefficient of $\left(r^{2}>0.9987\right)$.
2.7.4. Accuracy. The accuracy of the assay method was evaluated in triplicate at three different concentration levels (0.1, 1.0 , and $2.5 \mu \mathrm{g} \mathrm{mL}^{-1}$ ), and the percentage recoveries were calculated.

2.7.5. Precision. The precision is usually reported as the percent relative standard deviation (\%RSD) of a set of responses. Precision was represented into two categories, namely, repeatability (intraday precision) and intermediate precision (interday precision).

2.7.6. Repeatability or Intraday Precision. Repeatability was tested by analyzing six determinations at three different concentrations, namely, low, medium, and high within the linearity range.

2.7.7. Intermediate or Interday Precision. The inter-day variability of this method was assessed over three days at three low, medium, and high concentrations of emtricitabine standard in replicates of six.

2.7.8. Pharmacokinetic Study in Rats. The pharmacokinetic studies were carried out in healthy male Wistar rats (200$250 \mathrm{~g}$ ), and the animals were fasted overnight before dosing with free access to water. The animals were acclimatized to laboratory conditions over the week before experiments and fed with standard rat diet, under controlled conditions of a $12: 12 \mathrm{~h} \mathrm{light:} \mathrm{dark} \mathrm{cycle,} \mathrm{with} \mathrm{a} \mathrm{temperature} \mathrm{of} 22 \pm 3^{\circ} \mathrm{C}$ and a relative humidity of $50 \pm 5 \% \mathrm{RH}$. The experimental protocol was approved by the Institutional Animal Ethical Committee (AACP/IAEC/Jun-2012-02).

Twelve rats were randomly separated into two groups (six animals each group). The grouping of animals was as follows:

Group I: control normal rats (received saline solution),

Group II: administered with pure drug (as solution) (15 mg/kg/rat) [16].

At regular time intervals $0,0.25,0.5,1,2,3,6,10,12,20$ and $24 \mathrm{~h}$ samples of blood were withdrawn $(100 \mu \mathrm{L})$ from the retro-orbital plexus by microcapillary technique under light ether anesthesia into heparinized microcentrifuge tubes (50 units heparin $/ \mathrm{mL}$ of blood). Plasma was separated by centrifugation at $12,000 \times \mathrm{g}$ for $15 \mathrm{~min}$ and analyzed by the following method. Plasma samples were deproteinated with $1 \mathrm{~mL}$ of acetonitrile, vortexed for $2 \mathrm{~min}$, and centrifuged at $12,000 \times \mathrm{g}$ for $10 \mathrm{~min}$. The supernatant was decanted into a China dish and evaporated to dryness at room temperature. This was further reconstituted with $100 \mu \mathrm{L}$ of mobile phase and vortexed for $30 \mathrm{~s}$ and $20 \mu \mathrm{L}$ was injected into an HPLC system. Emtricitabine was detected at a wavelength of $280 \mathrm{~nm}$.

\section{Results and Discussion}

3.1. Method Development and Optimization of HPLC-UV Conditions. A liquid chromatographic method for the estimation of emtricitabine in rat plasma has been developed 
and validated according to the principles of Good Laboratory Practices. An appropriate wavelength was important for good sensitivity. It is shown in Figure 1(a) that emtricitabine has a special conjugation structure which leads to strong UV absorption at the wavelength of $280 \mathrm{~nm}$. Therefore, the detection wavelength was set at $280 \mathrm{~nm}$. It was necessary to use an IS in extraction techniques and HPLC method to compensate for extraction variation, efficiency, and analytical errors. Lamivudine was adopted as the IS in this study for the reasons that it is structurally similar to emtricitabine and its behavioural characteristics and properties conform to the chemical requirement for IS in HPLC. In addition, lamivudine is commercially available in high purity, and it is stable and nonreactive with sample or mobile phase. Meanwhile, it also has good response at the detection wavelength of $280 \mathrm{~nm}$.

To acquire short run time and good resolution for both analyte and IS several trials were carried out to optimized the mobile phase. The feasibility of various combinations of solvents such as acetonitrile and methanol with altered flowrates (in the range $1-1.2 \mathrm{~mL} \mathrm{~min}^{-1}$ ) was investigated for complete chromatographic resolution of the emtricitabine with best sensitivity, efficiency, and peak shape. Methanol was selected as organic phase because of its least viscosity and has strong eluting power. Therefore, according to the chemical characteristics of emtricitabine and IS, appropriate concentration of acidic modifier, acetic acid added into mobile phase, and an increase in the methanol content could improve peak shape. An increase in the water content not only broadened the peak but also resulted in extremely rapid desorption and elution of emtricitabine.

Finally, it was found that a mixture of $10 \mathrm{mM}$ potassium dihydrogen phosphate buffer- (adjusted to $\mathrm{pH}$ 6.8) methanol$2 \%$ acetic acid in a ratio of $(73: 25: 2, \mathrm{v} / \mathrm{v} / \mathrm{v})$ with $\mathrm{pH}$ adjusted with orthophosphoric acid to 3.5 at a flowrate of $1 \mathrm{~mL} \mathrm{~min}^{-1}$ could achieve the above purpose that was found to be optimum and provided adequate peak separation, with less tailing and resulted in good resolution among all the other combinations tested which was finally adopted as the mobile phase.

3.2. Limit of Detection and Limit of Quantitation. Concentrations of LOD and LOQ were found to be 0.016 and $0.049 \mu \mathrm{g} \mathrm{mL} L^{-1}$, respectively.

3.3. Specificity. Specificity is expressed as the capability of a method to distinguish the analyte from all potentially intrusive substance. The specificity of the method was scrutinized by blank plasma detection, peak purity, and spiking blank plasma with pure standard compounds. Blank plasma had no interference, when emtricitabine and the IS were eluted. At optimized conditions, the separation of emtricitabine and lamivudine was completed within 8 min (Figure 2).

3.4. Linearity. Each sample was analyzed in replicates of six to verify the reproducibility of detector response at each concentration level. The detector responses were found to be linear over the concentration range from 0.050 to $3.0 \mu \mathrm{g} \mathrm{mL}^{-1}$ as portrays in Figure 3. The regression equation for the graph

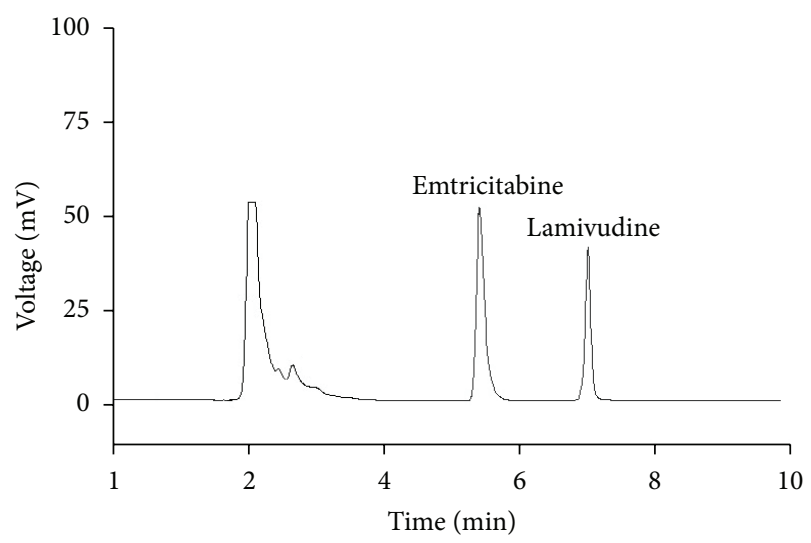

FIgURE 2: At optimized conditions: (a) chromatographic profile of the plasma spiked with emtricitabine $\left(2 \mu \mathrm{g} \mathrm{mL}^{-1}\right)$ in the presence of the I.S $\left(0.8 \mu \mathrm{g} \mathrm{mL}^{-1}\right)$.

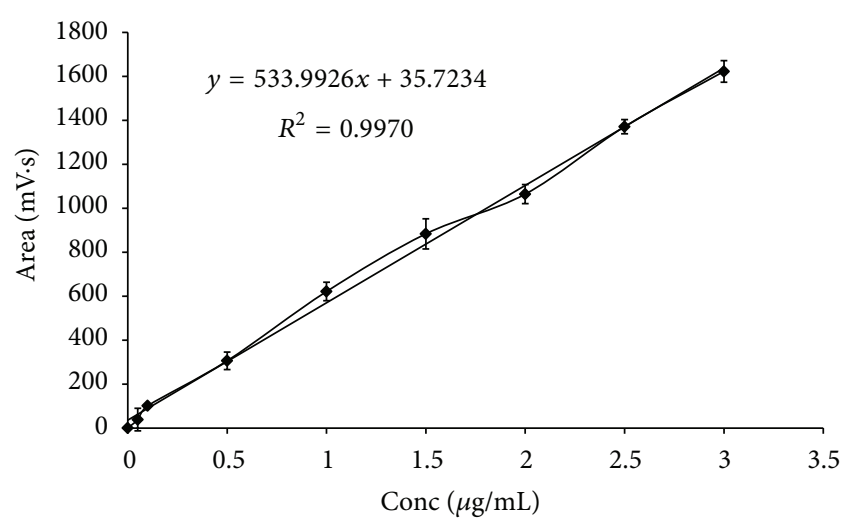

FIgURE 3: Linearity graph of emtricitabine at $0.050,0.1,0.5,1.5,1.0$, 2.0, 2.5 and $3.0 \mu \mathrm{g} \mathrm{mL}^{-1}$.

is $y=533.99 x+35.72$, and the correlation coefficient $R^{2}$ is 0.9970 showing excellent correlation between the area and the concentration.

3.5. Precision. The percentage relative standard deviation (\%RSD) of the area of emtricitabine during intraday study was found to be less than 5 and for interday study was found to be less than 6.5, which indicated a good precision of the method (Table 1). Intra-day and inter-day precision (\% R.S.D) of the methods were lower than $7 \%$ and were within the acceptable limits to meet the guidelines for bioanalytical method validation which is considered to be $\leq 15 \%[13,15]$.

3.6. Accuracy. The quantitative recovery of emtricitabine achieved ranged from 92.0 to $98.20 \%$ with a low \%RSD value. The results of the recovery experiments done at three concentration levels and the \%RSD values are given in Table 1.

3.7. Stability. Bench-top stability was investigated to ensure that emtricitabine was not degraded in plasma samples at room temperature for a time period to cover the sample 
TABLE 1: Intra-day and inter-day precision and accuracy of emtricitabine in rat plasma $(n=6)$.

\begin{tabular}{lccc}
\hline $\begin{array}{l}\text { Concentration } \\
\left(\mu \mathrm{g} \mathrm{mL}^{-1}\right)\end{array}$ & $\begin{array}{c}\text { Observed } \\
\text { concentration } \\
\left(\mu \mathrm{g} \mathrm{mL}^{-1}\right)\end{array}$ & Precision\% & Accuracy\% \\
\hline $\begin{array}{l}\text { Intraday } \\
0.1\end{array}$ & $0.097 \pm 0.003$ & 3.09 & 97.0 \\
1.0 & $0.982 \pm 0.044$ & 4.48 & 98.20 \\
2.5 & $2.465 \pm 0.078$ & 3.16 & 98.0 \\
Interday & & & \\
0.1 & $0.092 \pm 0.005$ & 5.45 & 92.0 \\
1.0 & $0.975 \pm 0.063$ & 6.46 & 97.50 \\
2.5 & $2.427 \pm 0.105$ & 4.32 & 97.08 \\
\hline
\end{tabular}

TABLE 2: Stability of emtricitabine in rat plasma $(n=6)$.

\begin{tabular}{lccc}
\hline $\begin{array}{l}\text { Sample } \\
\text { condition }\end{array}$ & $\begin{array}{c}\text { Spiked } \\
\text { concentration } \\
(\mu \mathrm{g} / \mathrm{mL})\end{array}$ & $\begin{array}{c}\text { Mean determined } \\
\text { concentration } \\
(\mu \mathrm{g} / \mathrm{mL})\end{array}$ & Accuracy $(\%)$ \\
\hline $\begin{array}{l}\text { Bench-top } \\
\text { stability }\end{array}$ & 0.1 & 0.094 & 94.00 \\
\hline Freeze-thaw & 1.0 & 0.98 & 98.00 \\
stability & 2.5 & 2.42 & 96.80 \\
\hline One-week & 0.1 & 0.099 & 99.00 \\
stability $^{\star}$ & 1.0 & 1.03 & 103.00 \\
& 2.5 & 2.46 & 98.40 \\
\hline
\end{tabular}

* Exposed at ambient temperature $\left(25^{\circ} \mathrm{C}\right)$ for $4 \mathrm{~h}$.

- After three freeze-thaw cycles.

Stored at $-16^{\circ} \mathrm{C}$.

preparation. It was measured by divulging the QC samples to ambient laboratory conditions for $10 \mathrm{~h}$. Freeze-thaw stability was measured over three cycles. Because of the need for occasional delayed injection of extraction samples, the stability of reconstituted samples was assessed at ambient temperature for $24 \mathrm{~h}$. The freezer storage stability of emtricitabine rat plasma at $-20^{\circ} \mathrm{C}$ was evaluated by assaying QC samples at the beginning and one week later. All stability QC samples were analyzed in six replicates. The results indicated that emtricitabine had an acceptable stability under those conditions (Table 2).

3.8. Application of the Assay. The validated method was successfully applied to investigate the content of emtricitabine in in vivo, after administered orally to rats. Oral administration of emtricitabine in the present study resulted in a sharp $C_{\max }$ of $1.357 \mu \mathrm{g} \mathrm{mL}^{-1}$ within $2 \mathrm{~h}$ after which the plasma concentration declined rapidly, indicating a rapid absorption of emtricitabine. The areas under the concentration versus time curve were $12.175 \mu \mathrm{g} \mathrm{mL}^{-1} * \mathrm{~h}$. The representative chromatogram of a plasma sample, which was collected from Wistar rats $2 \mathrm{~h}$ following oral administration of emtricitabine as portrays in Figure 4. The plasma profile of emtricitabine

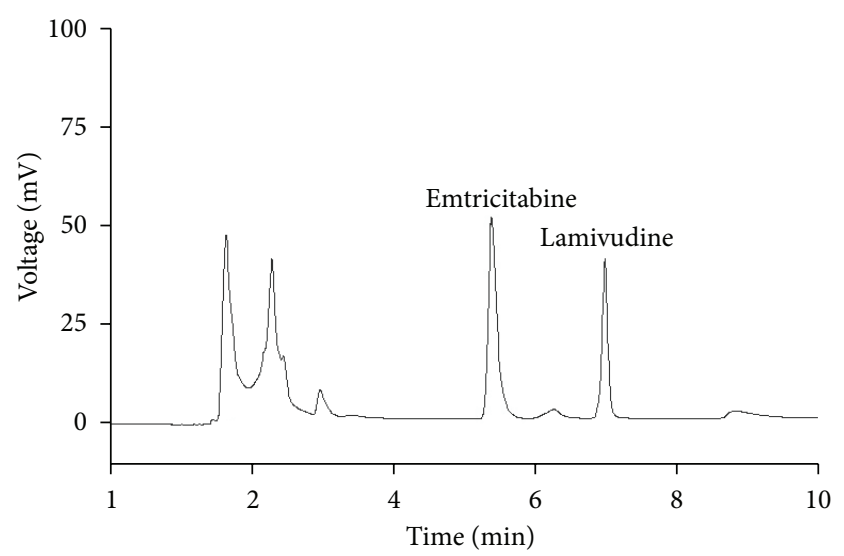

FIGURE 4: Chromatogram of plasma sample collected from rats $2 \mathrm{~h}$ after oral administration of emtricitabine.

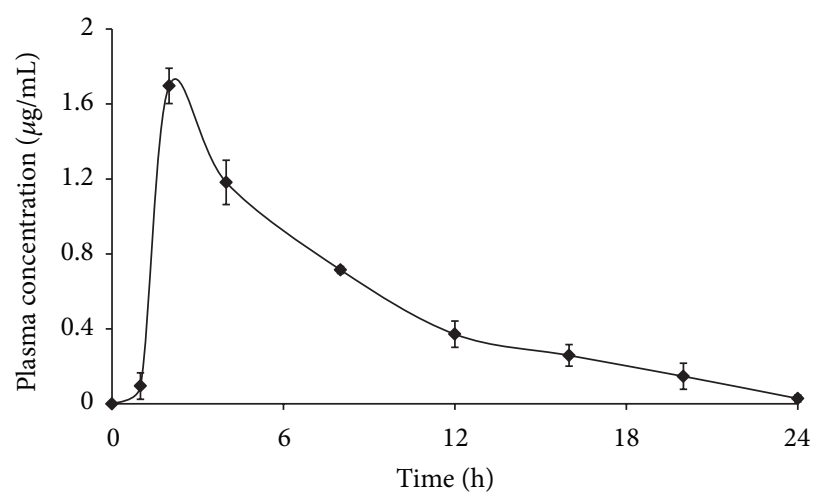

FIGURE 5: Plasma concentration-time curve of emtricitabine after being orally administered male Wistar rats at dose of $15 \mathrm{mg} / \mathrm{kg} / \mathrm{rat}$ $(n=6$, mean \pm S.D $)$.

TABLE 3: Pharmacokinetic parameters of emtricitabine at a dose of $15 \mathrm{mg} / \mathrm{kg} / \mathrm{rat}$.

\begin{tabular}{lc}
\hline Pharmacokinetic parameters & Emtricitabine \\
\hline$C_{\max }\left(\mu \mathrm{g} \mathrm{mL}^{-1}\right)$ & $1.357 \pm 0.029$ \\
$t_{\max }(\mathrm{h})$ & $2.0 \pm 0.007$ \\
$t_{1 / 2}(\mathrm{~h})$ & $8.153 \pm 0.670$ \\
$\mathrm{AUC}_{0-24}\left(\mu \mathrm{g} \mathrm{mL}^{-1} * \mathrm{~h}\right)$ & $12.175 \pm 0.326$ \\
$\mathrm{AUMC}_{0-24}\left(\mu \mathrm{g} \mathrm{mL}^{-1} * \mathrm{~h}\right)$ & $163.51 \pm 24.038$ \\
$K_{e}(1 / \mathrm{h})$ & $0.0681 \pm 0.007$ \\
$\mathrm{MRT}$ & $15.6 \pm 0.743$ \\
\hline
\end{tabular}

Data presented as mean \pm standard deviation $(n=6)$.

is shown in Figure 5. The results substantiate the suitability of the developed method for determining emtricitabine concentration in plasma after oral administration. The pharmacokinetic data of emtricitabine after oral administration in rats is shown in Table 3. 


\section{Conclusion}

A specific, linear, accurate, reliable, and reproducible new method of emtricitabine in rat plasma was developed and fully validated over the range $0.050-3.0 \mu \mathrm{g} \mathrm{mL}^{-1}$ with LOQ of $0.049 \mu \mathrm{g} \mathrm{mL}^{-1}$. The method was successfully applied to measure the drug concentration in plasma after oral administration to rats. Such low LOQ is very important for pharmacokinetic study of sustained release oral formulations, where a drug concentration in blood is very low at several time points. Reproducible high recovery of emtricitabine was achieved. Because of its highly satisfactory sensitivity, accuracy, linearity, and specificity, this HPLC methodology could thus be an appropriate tool for further determination of emtricitabine in plasma samples in the pharmacokinetic studies.

\section{Conflict of Interests}

The authors declare no conflict of interests.

\section{Acknowledgments}

The authors gratefully acknowledge financial support and granting research fellowship (45/38/2011/Nan-BMS) from Indian Council of Medical Research, Govt of India, New Delhi (ICMR). The authors are also grateful to Cipla Laboratories, Mumbai, India, for providing the gift samples of emtricitabine and lamivudine.

\section{References}

[1] L. H. Wang, A. A. Wiznia, M. H. Rathore et al., "Pharmacokinetics and safety of single oral doses of emtricitabine in human immunodeficiency virus-infected children," Antimicrobial Agents and Chemotherapy, vol. 48, no. 1, pp. 183-191, 2004.

[2] P. D. Hamarapurkar and A. N. Parate, "HPLC method for the determination of emtricitabine and related degradation substances," The Journal of Chromatographic Science, vol. 51, no. 5, pp. 419-424, 2013.

[3] Y. van Herrewege, J. Michiels, J. van Roey et al., "In vitro evaluation of nonnucleoside reverse transcriptase inhibitors UC781 and TMC120-R147681 as human immunodeficiency virus microbicides," Antimicrobial Agents and Chemotherapy, vol. 48, no. 1, pp. 337-339, 2004.

[4] K. Terrazas-Aranda, Y. van Herrewege, P. J. Lewi, J. van Roey, and G. Vanham, "In vitro pre- and post-exposure prophylaxis using HIV inhibitors as microbicides against cell-free or cell-associated HIV-1 infection," Antiviral Chemistry and Chemotherapy, vol. 18, no. 3, pp. 141-151, 2007.

[5] S. di Fabio, J. van Roey, G. Giannini et al., "Inhibition of vaginal transmission of HIV-1 in hu-SCID mice by the non-nucleoside reverse transcriptase inhibitor TMC120 in a gel formulation," AIDS, vol. 17, no. 11, pp. 1597-1604, 2003.

[6] A. Darque, G. Valette, F. Rousseau, L. H. Wang, J.-P. Sommadossi, and X.-J. Zhou, "Quantitation of intracellular triphosphate of emtricitabine in peripheral blood mononuclear cells from human immunodeficiency virus-infected patients," Antimicrobial Agents and Chemotherapy, vol. 43, no. 9, pp. 22452250, 1999.
[7] N. L. Rezk, R. D. Crutchley, and A. D. M. Kashuba, "Simultaneous quantification of emtricitabine and tenofovir in human plasma using high-performance liquid chromatography after solid phase extraction," Journal of Chromatography B, vol. 822, no. 1-2, pp. 201-208, 2005.

[8] A. K. Peepliwal and C. G. Bonde, "Determination of emtricitabine in human plasma by RP-HPLC with UV-detection," Journal of Pharmacy Research, vol. 3, no. 8, pp. 1712-1715, 2010.

[9] N. A. Gomes, V. V. Vaidya, A. Pudage, S. S. Joshi, and S. A. Parekh, "Liquid chromatography-tandem mass spectrometry (LC-MS/MS) method for simultaneous determination of tenofovir and emtricitabine in human plasma and its application to a bioequivalence study," Journal of Pharmaceutical and Biomedical Analysis, vol. 48, no. 3, pp. 918-926, 2008.

[10] A. Karunakaran, K. Kamarajan, and V. Thangarasu, "A validated RP-HPLC method for simulataneous estimation of emtricitabine and tenofovir disoproxil fumarate in pure and in tablet dosage form," Der Pharmacia Sinica, vol. 1, no. 2, pp. 52-56, 2010.

[11] P. S. Devrukhakar, R. Borkar, N. Shastri, and K. V. H. Surendranat, "A validated stability-indicating rp-hplc method for the simultaneous determination of tenofovir, emtricitabine, and an efavirenz and statistical approach to determine the effect of variables," ISRN Chromatography, vol. 2013, Article ID 878295, 8 pages, 2013.

[12] P. Kumar, S. C. Dwivedi, and A. kushnoor, "A validated stability indicating RP-HPLC method for the determination of emtricitabine in bulk and capsules," Farmacia, vol. 60, no. 3, pp. 402-410, 2012.

[13] C. Mathew, M. Ajitha, and P. R. S. Babu, "Cefpodoxime proxetil: a new stability indicating RP-HPLC method," ISRN Chromatography, vol. 2013, Article ID 328157, 8 pages, 2013.

[14] Food and Drug Administration, Guidance for Industry: Bioanalytical Method Validation, US Department of Health and Human Services, FDA, Center for Drug Evaluation and Research, Rockville, Md, USA, 2001.

[15] ICH Harmonised Tripartite Guideline: Validation of Analytical Procedures: Methodology, Q2 (R1), International Conference on Harmonisation of Technical Requirements for Registrations of Pharmaceuticals for Human Use, ICH, Geneva, Switzerland, 2005.

[16] R. Nirogi, G. Bhyrapuneni, V. Kandikere et al., "Pharmacokinetic profiling of efavirenz-emtricitabine-tenofovir fixed dose combination in pregnant and non-pregnant rats," Biopharmaceutics \& Drug Disposition, vol. 33, no. 5, pp. 265-277, 2012. 

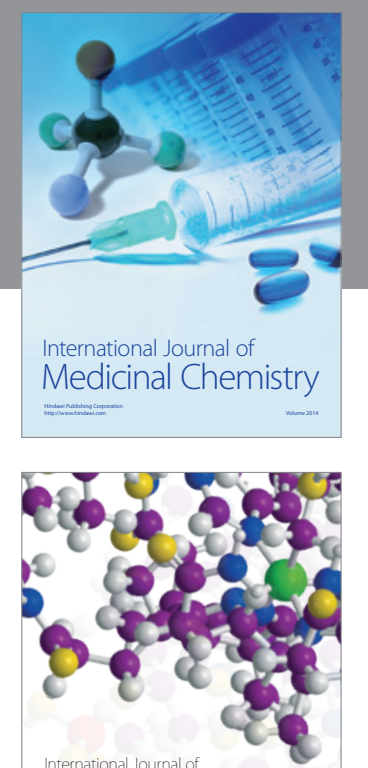

\section{Carbohydrate} Chemistry

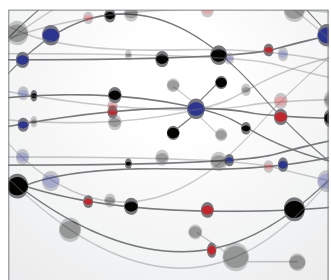

The Scientific World Journal
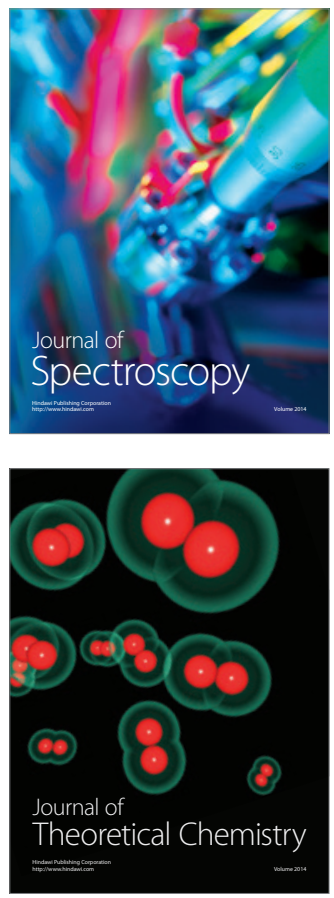
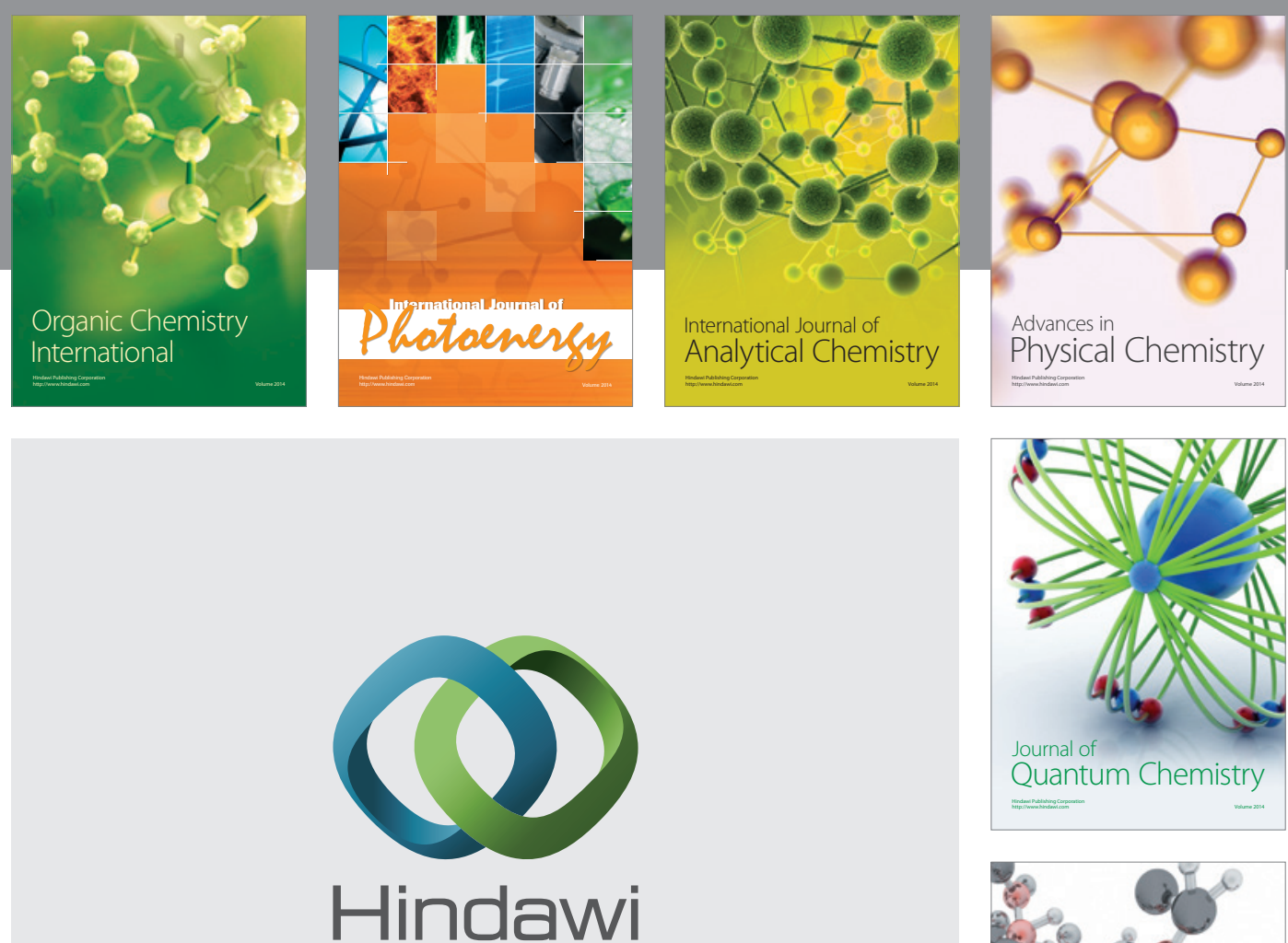

Submit your manuscripts at

http://www.hindawi.com

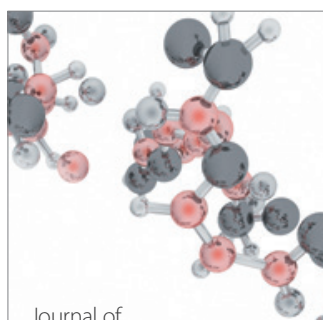

Analytical Methods

in Chemistry

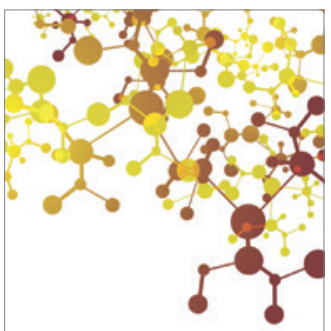

Journal of

Applied Chemistry

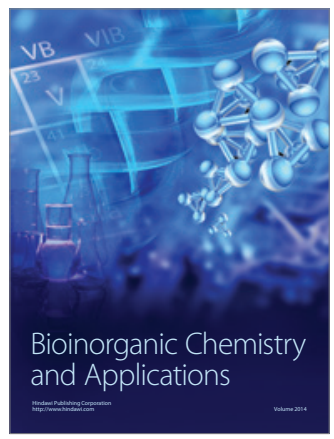

Inorganic Chemistry
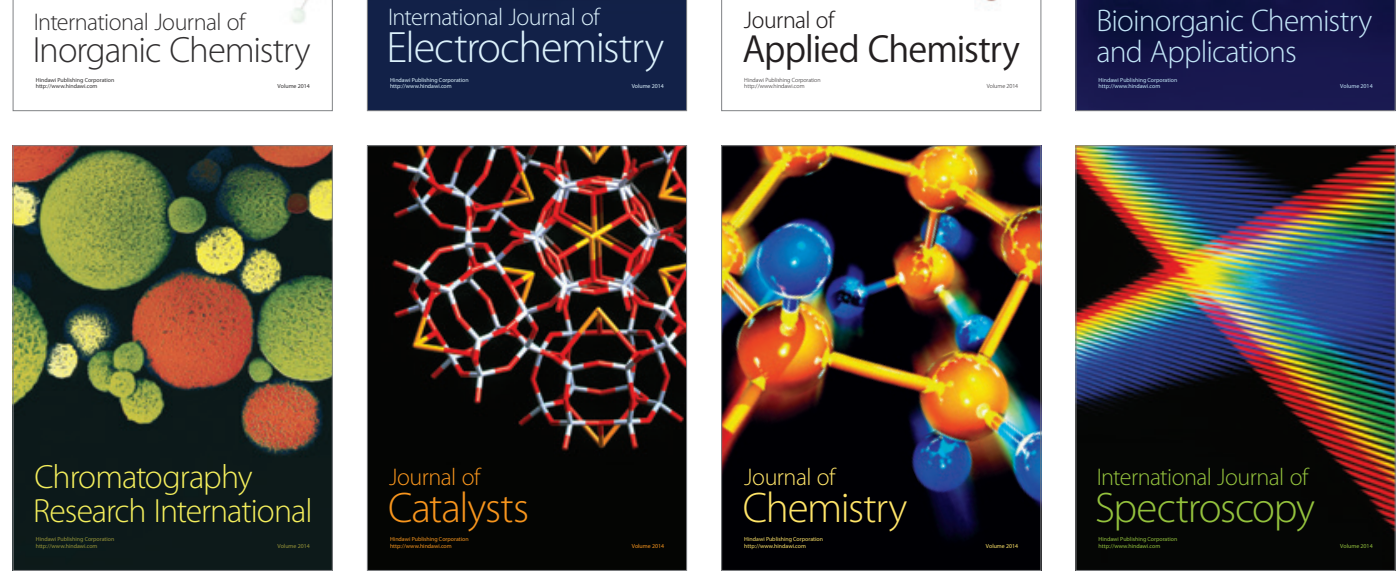